Cinémas

Revue d'études cinématographiques

Journal of Film Studies

\title{
Parutions récentes Recently Published
}

Volume 15, numéro 1, automne 2004

Entre l'Europe et les Amériques

URI : https://id.erudit.org/iderudit/011665ar

DOI : https://doi.org/10.7202/011665ar

Aller au sommaire du numéro

Éditeur(s)

Cinémas

ISSN

1181-6945 (imprimé)

1705-6500 (numérique)

Découvrir la revue

Citer ce document

(2004). Parutions récentes. Cinémas, 15(1), 169-170.

https://doi.org/10.7202/011665ar d'utilisation que vous pouvez consulter en ligne.

https://apropos.erudit.org/fr/usagers/politique-dutilisation/ 


\section{Parutions récentes/ Recently Published}

AUMONT, Jacques (dir.), Les Voyages du spectateur, Paris, Léo Scheer/Cinémathèque française, 2004, 338 p.

AUMONT, Jacques (dir.), Le Septième Art, Paris, Léo Scheer, 2003, 370 p.

BAETENS, Jan et Marc LITS (dir.), La Novellisation. Du film au livre/Novelization. From Film to Novel, Leuven, Leuven University Press, 2004, 246 p.

BARNIER, Martin, Des films français made in Hollywood. Les versions multiples 1929-1935, Paris, L'Harmattan, 2004, 273 p.

CHEVALDONNÉ, Yves, Nouvelles techniques et culture régionale. Les premiers temps du cinéma dans le Vaucluse (18961914), Québec, PUL, 2004, 227 p.

ESQUENAZI, Jean-Pierre, Cinéma contemporain, état des lieux, Paris, L'Harmattan, 2004, $310 \mathrm{p}$.

GAUDREAULT, André, Catherine RUSSEL et Pierre VÉRONNEAU (dir.), Le Cinématographe, nouvelle technologie du XX siècle/The Cinema, a New Technology for the 20th Century, Lausanne, Payot Lausanne, 2004, 399 p.

GAUTHIER, Guy, Un siècle de documentaires français, Paris, Armand Colin, 2004, 235 p.

GÉNIN, Bernard, Le Cinéma d'animation, Paris, Cahiers du cinéma, 2003, $95 \mathrm{p}$.

GUÉRIN, Marie Anne, Le Récit de cinéma, Paris, Cahiers du cinéma, 2003, $96 \mathrm{p}$.

GOZILLON-FRONSACQ, Odile, Cinéma et Alsace. Stratégies cinématographiques 1896-1939, Paris, AFRHC, 2003, 447 p.

HUGLO, Marie-Pascale et Sarah ROCHEVILLE, Raconter? Les enjeux de la voix narrative dans le récit contemporain, Paris, L'Harmattan, 2004, 183 p.

JEANNERET, Yves et Nathalie ROELENS (dir.), L'Imaginaire à l'écran/Screen Imaginary, Amsterdam/New York, Rodopi, 2004, $264 \mathrm{p}$. 
LEFEBVRE, Thierry, La Chair et le celluloïd. Le cinéma chirurgical du Docteur Doyen, Brionne, Jean Doyen Éditeur, 2004, $144 \mathrm{p}$.

LOIPERDINGER, Martin (dir.), Celluloid Goes Digital. Historical-Critical Editions of Film on DVD and the Internet, Trier, WVT, 2003, $152 \mathrm{p}$.

MAGNY, Joël, Vocabulaires du cinéma, Paris, Cahiers du cinéma, 2004, $95 \mathrm{p}$.

MARIE, Michel et Laurent LE FORESTIER, La Firme Pathé Frères 1896-1914, Paris, AFRHC, 2004, $446 \mathrm{p}$.

PERRON Bernard et Mark J. P. WOLF (dir.), The Video Game Theory Reader, New York, Routledge, 2003, 343 p.

PREDAL, René, Sans toit ni loi d'Agnès Varda, Neuilly, Atlande, 2003, $120 \mathrm{p}$.

SCHULZE, Brigitte, Humanist and Emotional Beginnings of a Nationalist Indian Cinema in Bombay. With Kracauer in the Footsteps of Phalke, Berlin, Avinus, 2003, 419 p.

THOMAS, Erika, L'Univers de Ken Loach. Engagement politique et rencontre amoureuse, Paris, L'Harmattan, 2004, 98 p.

TOMAS, David, Beyond the Image Machine. A History of Visual Technologies, London/New York, Continuum, 2004, 231 p. 